\title{
Business Coaching: Implementation of Service Quality and Social Media Promotion Improvement in Indonesian MSMEs' Restaurant
}

\author{
Helmi Yulianto ${ }^{1}$, Hasnul Suhaimi ${ }^{2}$ \\ \{botelaw@yahoo.com ${ }^{1}$, hasnuls@gmail.com² \} \\ Faculty of Economics and Business, University of Indonesia, Salemba, Jakarta Pusat, Indonesia ${ }^{1}$, \\ Faculty of Economics and Business, University of Indonesia, Salemba, Jakarta Pusat, Indonesia ${ }^{2}$
}

\begin{abstract}
This paper aims to assist an Indonesian MSME restaurant in managing its marketing activities by implementing a strategy to increase their service quality and promotion. Business coaching method, a qualitative research, was conducted for eight months to find out the actual condition and problems, and then take actions agreed by the MSME to overcome such problems. After conducting several external and internal analysis, including BMC, PESTEL, Porter's Five Forces, STP, 7Ps, and DINESERV mini survey, it is revealed that MSME are facing several problems. Customer gaps, especially in intangible dimension, and ineffective promotion activities were found. Gaps analysis and pareto analysis confirms those problems are the most important and feasible to be solved. Therefore, reducing customer gap through implementation of service standard operating procedure (SOP) and introduction to service excellence knowledge is conducted. Optimization of MSME's promotion activities through Instagram also implemented, which successfully improve their exposure and customer engagement.
\end{abstract}

Keywords: Business Coaching, Service Quality, Social Media Promotion.

\section{Introduction}

In Asian developing country like Indonesia, micro, small and medium enterprises (MSMEs) have made significant contributions not only to its national's gross domestic product (GDP), but also in terms of its shares in number of enterprises, employment generation, and regional dispersal of industry. Unfortunately there are many constraints faced by MSMEs both from external and internal. Many of them are struggling to sustain or to grow due to problems they have faced, especially lack of access to get financial credit from bank, limited access to advanced technologies and comprehensive information, also limitation in business management skill [1].

One of business sector in Indonesia that shows an increase in GDP growth rate and high number of business unit is food and beverage sector, thus the level of competition in this sector is quite high. However, the high rate of household consumption in this sector is also high, and it will give the potential for greater opportunities.

There are several studies regarding to the problem faced by MSMEs [2] including their service quality problems [3][4] and promotion problems [5][6], however this study intends to focus on one of the MSME and help them to overcome the problems they face. Even though there have been similar previous studies focuses to other MSME, however, the problems of 
each MSME are unique, therefore each MSME requires specific analysis and solutions which also vary according to the problems it faces.

Casablanca Kebab (CK) which was founded in 2006 is an example of the MSMEs who competes in food and beverage sector. Their revenue mainly generated from sales in their one and only outlet. Unfortunately, they also faced MSMEs' common problems and limitations which includes their service quality level and ineffective promotion activities. Therefore it is necessary to understand the actual condition of $\mathrm{CK}$ in order to find the solution for their problems through several internal and external analysis.

Although there are many problems faced by MSMEs, this study will only focus on improvement of several aspects that important and feasible for culinary MSMEs to improve, which are service quality [7] and social media promotion [5]. Good service quality leads to customer satisfaction and it will significantly affect customer loyalty [8]. On the other hand, promotion through social media is considered as one of the most cost effective way to generating exposure, upselling, building partnership, and improving customer engagement [9]. Based on the abovementioned background, this study aims to: (1) identify and analyze the actual condition of MSMEs' service quality and social media promotion activities, and (2) seek and implement the feasible solution that required to improve MSMEs' service quality and social media promotion. Hopefully this study will be able to increase CK's competitive advantage and in general it can enrich the knowledge about how to level up the MSMEs.

\section{Literature Review}

\subsection{Service Quality}

Service quality is one of the most important aspect for restaurant business success [10], especially in an increasing competitive environment. Delivering a quality service is crucial in order to attract new customers, retain the existing one, and remain competitive and profitable [11]. In general, service quality is defined as the gap between the customers' expectation about a service and their perception of the way the service has been performed [12].

To improve the service quality, it is necessary to understand the actual condition of current service quality as a starting point. Various measurement techniques for evaluating service quality have been developed and used in literature. However one of the most popular is the SERVQUAL model which measures five service quality dimensions consist of tangibles, reliability, responsiveness, assurance, and empathy [12]. SERVQUAL model is considered as a generic tool with good validity and reliability, and it also can be applied in various industries [13]. However, it has some limitations. In order to measure the service quality in restaurant, Stevens, Knutson and Patton [14] then modify the SERVQUAL by developing the DINESERV instrument. This measurement tool then used by many authors to assess the restaurants' service quality, recently it was used in Indonesia [15], Korea [16], and even Italy [10].

Both SERVQUAL and DINESERV are using similar approach to measure the service quality. They are assessing the differences between customer expectation and their perception to the actual service performance (the customer gap) in all service quality dimensions. Although the main focus of these models is the customer gap, Zeithaml, Bittner and Gremler [17] identified that there are four other gaps which might be the potential causes of a firm 
could not meet their customer expectation (the provider gaps). Therefore, in order to close the customer gap, it is required to identify and close these provider gaps.

The first gap is the listening gap, which shows the difference between customer expectations for a service and company's understanding of those expectations. The second gap is the design and standards gap, which reflects the difference between what company's perceives to be the customers' expectation and the service quality standards that are put into place. The third gap is the performance gap, the discrepancies between the service standard set by company and actual service delivery. The fourth gap is the communication gap, which focuses on the discrepancies between service delivery and what was promised or communicated externally to customer.

Although there are strategies provided to reduce the discrepancies in each gaps, but it does not mean that all of those strategies can be applied automatically in any level of company, especially in MSMEs level. Those provided strategies were based on big and fully established firms which have capabilities to apply such strategies. Service operator's perspective [16] and firms' capabilities [18] shall be taken into account in determining service quality improvement strategy. Several strategies that can be used by MSMEs are including strategic use of complaints, standardizing tasks and service delivery, technical and interpersonal training [18], and introducing a customer oriented service to its employees [19].

\subsection{Social Media Marketing}

Promotion through social media considered as one of the most cost effective way to generating exposure, upselling, building partnership, and improving customer engagement [9]. Thus it is fit for MSMEs condition. As a two-way communication channel [20], the engagement rate such as number of likes, comments and shares can be used to measure the effectiveness of social media [21]. Like any other promotions, social media promotion strategy need to be developed carefully.

In order to have an effective promotion, Lovelock and Wirtz [22] developed an integrated service communication model which offers a useful checklist for marketing communication planning. This model starts with $5 \mathrm{Ws}$ questions to know the target audience, the content and objective, how to communicate, channels to communicate, and the best time to communicate. Several guidance such as how to create an attractive profile bio [23], how to conduct an audit to Instagram profile [24], effective content [21], and best times to post [25] also shall be taken into account when creating effective social media promotion strategy. Those several previous studies provides a generic guidance for firms in their social media strategy, however it have not tested in one specific MSMEs firm with its unique problem and conditions. Therefore to be fit for some specific MSMEs, these strategies shall take into account MSMSs' needs and capabilities to be applied.

\section{Method}

This study is a descriptive qualitative research and will be conducted through a business coaching method. The object of this study is CK, a MSME restaurant located in Jakarta, Indonesia which provide several Middle-East dish, especially kebab. Both primary and secondary data were utilized which acquired from interviews, observations, mini survey using DINESERV questionnaire, and CK's internal data. The primary data was acquired through unstructured interviews with CK's owner and its employees, conducting direct observations in 
their offline store with unstructured observation technique, and also through DINESERV mini-survey which applying accidental sampling method to 30 respondents. The DINESERV mini-survey was conducted in order to get customers' point of view regarding to CK's service quality by using the generic questionnaire provided by Stevens, Knutson and Patton [14]. While the secondary data was obtained from CK's internal data and also from previous literature studies such as research journals, articles and books.

The study was executed in around eight months through four steps of business coaching framework, which consist of: (1) internal \& external analysis; (2) TOWS, gaps analysis, and pareto analysis; (3) alternative solutions and decision making; and (4) implementation and monitoring. Through this framework, the actual and comprehensive conditions and problems of MSME will be able to be identified, analyzed, and confirmed, including which problems were the most important yet urgent and feasible to be solved. This framework will also be able to seek and develop several alternative solutions that feasible to be applied and also fit for the problems faced by $\mathrm{CK}$ which then will be implemented.

\section{Results And Discussions}

Several tools and frameworks were utilized to analyze MSMEs' internal and external factors in order to get a clearer insight regarding to CK's actual business condition. In addition, since knowing what customer expect is very critical in a service business [18], mini survey using DINESERV questionnaire was conducted to get not only customer expectation, but also customer perceived quality. DINESERV is a multi-dimensional measurement scale which able to capture customers' expectation and perceptions with its 29 item of questions that covers all five service quality dimensions.

The result shows that there are negative gaps between customer expectations compared to their service quality perceptions. There are only five of 29 items got positive gap, and four of them are in the tangibles dimension. However, even for tangibles dimension the average gap is still negative although the value is quite low.

Table 1. Customer Gaps.

\begin{tabular}{ll}
\hline Dimension & Gap \\
\hline Tangibles & -0.127 \\
Reliability & -0.953 \\
Responsiveness & -1.009 \\
Assurance & -0.674 \\
Empathy & -0.725 \\
\hline
\end{tabular}

Further, we analyze the provider gaps. Interview with CK management was conducted to get insight about the provider gaps that might occurs. Regarding to the listening gap, they never conduct any customer survey, but they are quite often have conversations with their customers. In general they already have a good understanding about what their customers' expectation. Moving to the design and standard gap, it is confirmed that service standard is absence. Without this standard and guidance, the service performance is depend on employees' individual factors who provide the service. Without standard being set by CK's management, it is quite hard to measure the performance and communication gap, therefore 
the attempt to improve CK's service quality shall starts from this existing design and standard gap.

Considering the result from several analysis were conducted, SWOT analysis and TOWS matrix was developed. There are several strategies developed under TOWS matrix, however this study will only focus on WT (weakness-threats) strategies that avoid threats and minimize weaknesses. Further analysis then conducted through Gap analysis combined with Pareto analysis, which confirms the importance and the urgency of the strategies to be taken. The result then presented to CK's management as the alternative solutions for their service quality and promotion activities as the most important and urgent problems. Upon discussion, it is agreed that the strategies which will be executed are: (1) implementation of service quality improvement through service standard operating procedures (SOP) and introduction of basic knowledge of service excellence, and (2) to improve their promotion activities through social media especially Instagram.

\subsection{Service Quality Improvement}

As agreed with CK's management, the endeavor to improve service quality will be conducted through implementation of service SOP and introducing service excellence knowledge to their employees. The first strategy is by developing and implementing service SOP which will be used as a guidance for CK's employee to deliver the service. In order to close the design and standard gap, the developed service SOP must be focus to and be oriented toward customer expectation. Analysis regarding to the actual flow or process about how CK deliver the service to its customer was conducted. The compatibility of each procedure to CK's customer expectation was then evaluated. This is to identify in which steps customer expectation was met and which ones need to be improved.

In developing the new service SOP, the result from DINESERV mini survey was used as a reference, especially for those components that considered as very important by customers. Besides the customer expectation, the new developed SOP shall also consider CK's capabilities, including its human resources and service scape. Nine service SOP were developed which categorized as: (1) greeting procedure; (2) delivering menu procedure; (3) taking order procedure; (4) input the order procedure; (5) food serving procedure; (6) table clearing procedure; (7) payment procedure; (8) cleaning procedure; and (9) online delivery procedure. These procedures then tested to couple of employees to confirm that it is easy to understand and doable.

There are several changes between the previous procedures and the new ones, and some of them can be deemed as a major changes. Thus socialization was conducted, assisted by appointed professional trainer, to ensure that all employees are familiar with this new service procedures. This socialization also aims to reduce the employees' resistance to the changes [26]. Upon the socialization, these new procedures was implemented in two stages. The first stage is the monitoring stage. Employees are still reminded and assisted to execute the procedures, and examples were still given both by CK's management and researcher. The next stage is the real implementation, where employees are needed to implement the procedures by them self.

Other strategy that being implemented to improve the service quality is by giving basic knowledge regarding to service excellence to CK's employees. It is agreed that this strategy will be executed through training and monitoring. The first step is developing the training concept which include all service excellence elements such as delivering the promise, dealing well with problems and queries, providing a personal touch, and going extra miles [27]. However, it should fit with CK's condition. The training was conducted through a professional 
trainer appointed by CK's management. Then it was continued by internalization stage which monitored by the trainer along with the SOP's monitoring stages.

\subsection{Social Media Promotion Improvement}

CK's current promotion is mainly conducted through discount and product bundling at their offline store. Actually CK already have an Instagram business account, but it was not utilized properly. Their postings were sporadic and unplanned. Considering this condition, the strategy to improve CK's Instagram promotion then developed. The Integrated Service Communications Model [22] was applied in developing this promotion strategy. The first step is defining the target audience and communication objective. Target audience was set to be in line with CK's segmentation strategy, while the communication objectives is to improve CK's exposure and customer engagement in their social media account.

Next step is determining the implementation strategy, including the message, channel, and timing. In order to have a good quality of content, several action was taken, including hiring a professional photographer to get a better picture quality, improving the profile bio, ensure the consistency of their color palette, also applying effective hashtag and captions in every posts. Several information, including rule of thumb and Instagram insight, were taken into account to determine the channel and time of post. Biweekly planning and schedule is applied for each future posts to ensure the continuity and its consistency with the marketing strategy. However, these strategies shall consider CK's financial budgetary, corporate design, and corporate marketing strategy.

Implementation of Integrated Service Communications Model in CK's social media promotion strategy resulting in improvement of their social media statistics. Table 2 shows the improvement of CK's social media during first three months implementation. There are quite significant improvement in CK's Instagram account exposures and audience engagements.

Table 2. Social Media Improvements.

\begin{tabular}{lccc}
\hline & Before & After & Improvements \\
\hline Followers & 666 & 1,052 & $58.0 \%$ \\
Total Posts & 41 & 78 & $90.2 \%$ \\
Like/post avg. & 31.8 & 42.2 & $32.7 \%$ \\
Share/post avg. & 0.3 & 0.8 & $166.7 \%$ \\
Reach/post avg. & 512.2 & $1,007.1$ & $96.6 \%$ \\
Profile visit/post avg. & 4.8 & 13.3 & $177.1 \%$ \\
\hline
\end{tabular}

\section{Conclusion}

Through business coaching, it is revealed that CK are facing several typical problems to MSMEs. These problems are including the existence of customer gaps and ineffective social media promotion. Several strategies were developed in order to overcome these problems, however such strategies shall take into account MSMEs' capabilities. Developing and implementing service SOP and introducing service excellence knowledge to its employees was taken as an effort to improve their service quality. Further, there are improvement on CK's social media exposure and engagement upon implementation of integrated service communications model [22]. Based on those result, hopefully this study will provide an 
additional insight regarding to the application of service quality improvement strategy and social media promotion strategy in MSMEs level especially in restaurant sector.

Based on external and internal analysis that has been conducted, there are several other issues that actually faced by CK as an MSMEs, such as financial reporting system, human resources management, and operational facilities. However this study only focus to service quality and promotion aspects. Thus improvement in those other areas are still open and required in order to leverage MSMEs' position in their business competition.

\section{References}

[1] Simba, A. \& Thai, M.T.T. : Advancing Entrepreneurial Leadership as a Practice in MSME Management and Development. Journal of Small Business Management. 57:sup2, pp.397-416, DOI: https://doi.org/10.1111/jsbm.12481 (2019)

[2] Tambunan, T.T.H. : Development of micro, small and medium enterprises and their constraints: a story from Indonesia. Gajah Mada International Journal of Business Vol. 13, No.1, pp. 21-43 (2011)

[3] Phiri, M.A. \& Pillay, S. : Customer perceptions of service quality at small medium micro enterprises (MSME): the case of Crossley Holdings, Durban South Africa. Journal of Economics, 8:1, pp.1-17 (2017) DOI: https://doi.org/10.1080/09765239.2017.1305667 (2017)

[4] Prinsloo, C. : Is SERVQUAL an inclusive indicator of SMEs' service quality advantage during an economic downgrade? a South African case. Journal of Business and Retail Management Research (JBRMR). Vol. 12 (2), pp. 94-106 (2018)

[5] Srinivasan, R., Bajaj, R., \& Bhanot, S. : Impact of social media marketing strategies used by MSMEs on customer acquisition and retention. Journal of Business and Management, 18(1), 91101 (2016)

[6] Supriaddin, N., Abbas, B., Razak A., Anaam, N. \& Muthalib, D.A. : Marketing strategy of micro small and medium (MSME) in the framework of public welfare improvement in Southeast Sulawesi province. International Journal of Scientific \& Engineering Research. 9(1), pp.933-937 (2018)

[7] Gadelrab, R., \& Ekiz, E. : An investigation of key success factors for restaurant operations in Saudi Arabia. Journal of Tourism, Heritage \& Services Marketing, 5(2), pp.27-35 (2019)

[8] Bloemer, J. : Linking perceived service quality and service loyalty: a multi-dimensional perspective. European Journal of Marketing, 33(11, 12), pp.1082-1106 (1999)

[9] Si, Sajid. : Social media and its role in marketing. Business and Economics Journal, 7:203. DOI: http://dx.doi.org/10.4172/2151-6219.1000203 (2016)

[10] Lupo, T., \& Bellomo, E. : DINESERV along with fuzzy hierarchical TOPSIS to support the best practices observation and service quality improvement in the restaurant context. Computers \& Industrial Engineering, 137. DOI: https://doi.org/10.1016/j.cie.2019.106046 (2019)

[11] Wu, H.C. : An empirical study of the effects of service quality, perceived value, corporate image, and customer satisfaction on behavioral intentions in the Taiwan quick service restaurant industry. Journal of Quality Assurance in Hospitality \& Tourism, 14(4), pp.364-390 (2013)

[12] Parasuraman, A., Zeithaml, V.A., \& Berry, L. : SERVQUAL: A multiple-item scale for measuring consumers perceptions of service quality. Journal of Retailing, 64, pp.12-40 (1988)

[13] Parasuraman, A., Zeithaml, V.A., \& Berry, L. : Refinement and reassessment of the SERVQUAL scale. Journal of Retailing, 67(4), pp.420-450 (1991)

[14] Stevens, P., Knutson, B., \& Patton, M. : DINESERV: a tool for measuring service quality in restaurants. Cornell Hotel and Restaurant Administration Quarterly, pp.56-60. (1995)

[15] Rottie, R., Sukapto, P., \& Hariandja, J. : Peningkatan Kualitas Pelayanan Rumah Makan X dengan Integrasi Metode DINESERV, ZOT, dan QFD. Saintek, 1(1), pp.11-20 (2017)

[16] Kim, K-J \& Choi, K. : Bridging the perception gap between management and customers on DINESERV attributes: The Korean all-you-can-eat buffet. Sustainability, 11, 5212 (2019) 
[17] Zeithaml, V.A., Bitner, M.J., \& Gremler, D.D. : Services Marketing Strategy. In R. Peterson, \& R. Kerin, Wiley International Encyclopedia of Marketing: Marketing Strategy (Vol. 1, pp. 208218). Chichester, UK: John Wiley \& Sons (2010)

[18] Haksever, C., Cook, R.G., \& Chaganti, R. : Applicability of the gaps model to service quality in small firms. Journal of Small Business Strategy. 8(1), pp.49-66 (1997)

[19] Lopez, P.E.A., Solis, M.d-L.C., Castanon, L.A., \& Lopez A.G. : Impact of training on improving service quality in small provincial restaurants, Journal of Foodservice Business Research, 20(1), pp.1-14 (2016)

[20] Taiminen, H., \& Karjaluoto, H. : The usage of digital marketing channels in SMEs. Journal of Small Business and Enterprise Development, pp.633-651 (2015)

[21] Su, N., Reynolds, D., \& Sun, B. : How to make your facebook posts attractive - a case study of a leading budget hotel brand fan page. International Journal of Contemporary Hospitality Management, 27(8) (2015)

[22] Lovelock, C., \& Wirtz, J. : Service Marketing: People, Technology, Strategy (8th ed.). NJ: World Scientific (2016)

[23] Macarthy, A. : 500 social media marketing tips: essential advice, hints and strategy for business: Facebook, Twitter, Pinterest, YouTube, Instagram, Snapchat, LinkedIn, and more! Swansea, Wales: Andrew Macarthy (2018)

[24] Thomas, B. : Instagram Audit. Retreived on 10 April 2020, from https://later.com/blog/instagram-audit/ (2019)

[25] Arens, Elizabeth. : The best time to post on social media in 2020. Retrieved on 14 April 2020, from https://sproutsocial.com/insights/best-times-to-post-on-social-media/\#how (2020)

[26] Coch, L., \& French, Jr., J. : Overcoming Resistance To Change. Human Relations, 1, pp.512-532 (1948)

[27] Johnston, R. : The determinants of service quality: satisfiers and dissatisfiers. International Journal of Service Industry Management, 6(5), pp.53-71 (1995) 